\title{
Effect of different ripening stages on bioactive compounds and antioxidant capacity of wild Rosa laevigata Michx
}

\author{
Guofang XIE ${ }^{1,2 *}$, Jiajia WANG ${ }^{1,2}$, Xiaoyan XU ${ }^{1,2}$, Rui WANG ${ }^{1,2}$, Xiaoli ZHOU ${ }^{1,2}$, Zhigang LIU ${ }^{1,2}$
}

\begin{abstract}
Rosa Laevigata Michx., contents of bioactive components contribute to the health beneftis of consuming fresh, snacks and medicine, is widely used as the Chinese medicinal herbs. The effect of fruit ripening on the bioactive compounds and antioxidant capacity of Rosa laevigata Michx fruits was investigated. The results showed that, the bioactive compounds, including titratable acidity, reducing sugar, total ascorbic acid, total polyphenol and total flavonoids, significant changes occurred at different ripening stages. The contents of reducing sugar, total polyphenol and total flavonoids were directly proportional to the maturity. However, the content of titration acid and ascorbic acid is inversely proportional to the maturity. Antioxidant capacity and ROS inhibition are proportional to the maturity, and the antioxidant capacity of Rosa laevigata Michx significantly increase during maturity. The Rosa laevigata Michx fruits at fully ripe stage had higher healthcare and medicinal value.
\end{abstract}

Keywords: Rosa laevigata Michx.; ripening stages; bioactive compounds; antioxidant capacity.

Practical Application: Optimizing harvesting and postharvest management of Rosa laevigata Michx.

\section{Introduction}

Rosa laevigata Michx. (Jinyinzi) is an evergreen climbing shrub prevalently distributed throughout southern regions of China, including Guizhou, Hulan and Zhejiang (Liu et al., 2013a). Several studies have reported that contents of nutrition and antioxidant components such as rutin, flavone, flavonols, polysaccharose, saponins and vitamin $C$ contribute to the health beneftis of consuming fresh, snacks and medicine (Zhao et al., 2003; Chen \& Zhang, 2005; Xiao et al., 2011; Li et al., 2012; Liu et al., 2013b), and its fruit is widely used as the Chinese medicinal herbs. Numerous studies have demonstrated that Rosa laevigata Mich $x$ fruit has powerful antioxidant, Acetaminophen, hypolipidemic, hepato-protective and antithrombosis activities (Liu et al., 2010; Zhang et al., 2013a; Dong et al., 2014;), has the capability to treat chronic cough, frequent micturition, hyperpiesia and dermatogic diseases (Jia et al., 2012), the protective effects against paracetamol, high-fat diet, $\mathrm{CCl}_{4}$ and hydrogen peroxide -induced liver injury (Zhang et al., 2013b; Liu et al., 2014). A number of preharvest and postharvest factors affect the physico-chemical properties, nutritional value and antioxidant components in fruit and vegetables (Opara et al., 2012). Literature evidence showed that the polysaccharose, vitamin $\mathrm{C}$ and evaporability composition of Rosa laevigata Michx. were affected by ripening stages (Yao \& She,1991; Cai et al., 2011). Studies have also shown that Rosa laevigata Michx harvested at fully ripe stage exhibited the highest level of flavonoid, saponins and antioxidant activity (Liu et al., 2010; Zhang et al., 2013c; Dong et al., 2014).

Although the chemical composition of Rosa laevigata Michx fruits is relatively known, as far as we know no work was developed on how ripening stages influences fruit composition and their antioxidant activity. Understanding fruit physico-chemical properties and nutritional properties is important in the design of cost-effective and efficient postharvest handling equipment, optimization of bioprocesses in functional food manufacture, and drugs. There is currently a dearth of scientific information on the key nutrition changes that occur during ripeness of Rosa laevigata Mich $x$ that are widely grown in the Guizhou province of China to assist in optimizing harvesting and postharvest management. These fruits do not attain maturity simultaneously, coexisting in the same tree from green/yellow to red mature fruits. The most frequent situation during picking is to collect all fruits together when the majority is fully ripe. Hence, the aim of this work is to access the antioxidant ability of Rosa laevigata Michx fruits along ripening, by evaluation of bioactive compounds and antioxidant capacity.

\section{Materials and methods}

\subsection{Samples}

Fruit samples were collected in of January 2015, in the forestry Sinan County (Guizhou Provence, China)(Location:N27 43 , E108 $09^{\prime}$, Altitude: 756 m). A wild Rosa laevigata Michx fruit population constituted by different shrubs that grow in same agroclimatic condition and without any cultural intervention was selected. Immediately after harvest, the fruits were transported in to guizhou engineering research center for fruit processing and were divided into three batches based on visual observation of fruit colour, representing three ripening stages (unripe, intermediate and ripe, Figure 1a-c), ranging from green / golden to red, stored 


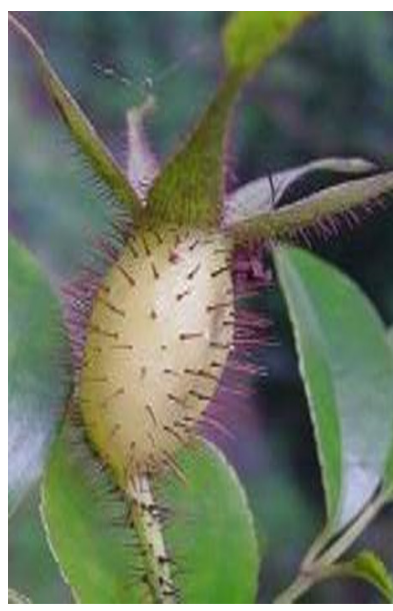

a) Unripe

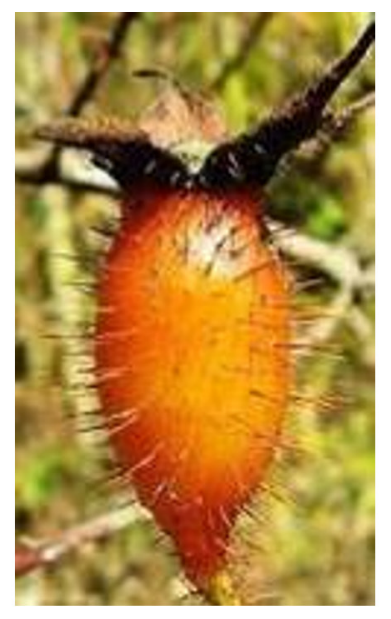

b) Intermediate

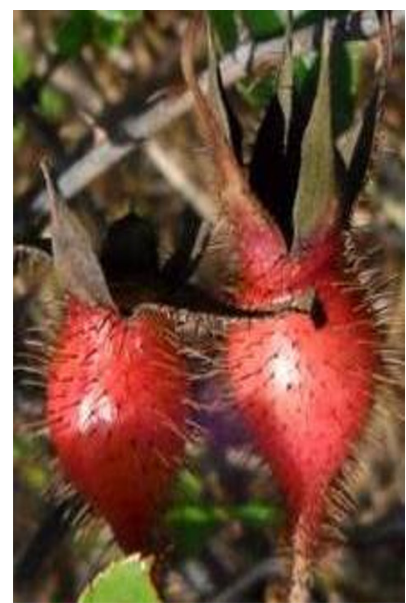

c) Ripe

Figure 1. Rosa laevigata Michx ripening stages considered in this work.

in refrigerator. A sample of 90 fruits was randomly selected (100 g from each maturity stage), respectively. The fruit were washed with distilled water and then homogenized using a lapping machine (Model A11, IKA, Germany) for analysis of bioactive compounds and antioxidant activity.

\subsection{Extraction conditions}

A fresh fruits $(5.0 \mathrm{~g})$ was extracted using $10 \mathrm{~mL}$ of $60 \%$ ethanol for $60 \mathrm{~min}$ with microwave- $\left(200 \mathrm{~kW}, 20^{\circ} \mathrm{C}\right)$ in a ultrasonic wave cleaner (model KQ5200DB; Kun Shan Ultrasonic Instruments Co., Ltd, Kunshan, Jiangsu, China) (EM60m). After filtration to remove the residual particles, the supernatants were combined in a flask and filled up to obtain $100 \mathrm{~mL}$ of extraction. The extractions were performed in triplicate. All the extracts were analyzed for total phenolic, and total flavonoids content effect on antioxidant activities (DPPH, FRAP, and total reducing power) and reactive oxygen species (ROS) $\left(\mathrm{H}_{2} \mathrm{O}_{2}, \mathrm{OH}-\right.$ and $\left.\mathrm{O}_{2}^{-}\right)$ scavenging capacity assay.

\subsection{Bioactive compounds content}

The titratable acidity (TA) were determined by $\mathrm{pH}$ Meter (model PHS-3C; INESA Scientific Instrument Co., Ltd, Shanghai, China), using $0.1 \mathrm{~N} \mathrm{NaOH}$ up to $\mathrm{pH}$ 8.1, results were expressed as g citric acid $\mathrm{kg}^{-1}(\mathrm{fw})$. The soluble protein (SP) content was measured according to coomassie brilliant blue G250 method (Xie et al., 2014), Bovine albumin was used as the standard and the results were expressed as mg Bovine Albumin Equivalents (BAE) / $100 \mathrm{~g}(\mathrm{fw})$. The reducing sugar (RS) content was measured according to 3,5-Dichlorosalicylic acid (DNS) method (Teixeira et al., 2012), results were reported as \% (fw). Total ascorbic acid (TAA) content was determined according to the method of Cao et al. (2007), results were reported as mg Ascorbic Acid Equivalents (AAE)/100 g (fw). Total polyphenol content (TPC) was quantified using Folin-Ciocalteu reagent (Nuncio-Jáuregui et al., 2015), Gallic acid was used as the standard and the results were expressed as mg Gallic Acid Equivalents (GAE) / $100 \mathrm{~g}(\mathrm{fw})$. Total flavonoids (TFs) were determined using the method developed by Dragović-Uzelac et al. (2010), rutin was used as the standard and the results were expressed as mg Rutin Equivalents (RE) /100 g (fw).

\subsection{Antioxidant activity}

The DPPH • scavenging activity of extracts was assessed according to the method described by Tauchen et al. (2015), the results are expressed as $\mu$ mol Trolox Equivalents (TE)/100 g (fw). The ferric ion reducing antioxidant power (FRAP) assay was done according to Todorovic et al. (2015), results were expressed as mean \pm standard error and units in $\mu \mathrm{mol}$ Trolox Equivalents (TE)/100 g (fw). The total reducing power assay (TRPA) was determined according to a previously described procedure (Oliveira et al., 2011), results were expressed as mean \pm standard error and units in Trolox Equivalents (TE) / $100 \mathrm{~g}$ (fw).

The superoxide radical scavenging activity was determined by the Autoxidation of Pyrogallol method (Xu et al., 2013). The hydroxyl radical scavenging activity (HRSA) and hydrogen peroxide scavenging activity (HPSA) of the samples was measured according to the method of Xie et al. (2011).

\subsection{Statistical analysis}

All sample characterization results were reported as mean \pm standard error. Statistical tests were performed using the SPSS ${ }^{\circledR}$ computer program, version 19.0 (SPSS Statistical Software, Inc., Chicago, IL, USA) to determine differences at the $5 \%$ level between different maturity stage using a one-way analysis of variance (ANOVA).

\section{Results and discussion}

\subsection{Bioactive compounds}

The extraction method (EM60m) was applied to the samples with different ripening stages (Figure 1a-c). The bioactive compounds of the three Rosa laevigata Michx varieties are presented in Table 1 . The titratable acidity content showed a 
Table 1. Bioactive compounds of fresh fruit of three ripe stage.

\begin{tabular}{lcccccc}
\hline & TA & $\begin{array}{c}\text { SP } \\
(\mathrm{g} \mathrm{CAE} / \mathrm{kg})\end{array}$ & $\begin{array}{c}\text { RS } \\
(\%)\end{array}$ & $\begin{array}{c}\text { TAA } \\
(\mathrm{mg} \mathrm{AAE} / 100 \mathrm{~g})\end{array}$ & $\begin{array}{c}\text { TPC } \\
(\mathrm{mg} \mathrm{GAE} / 100 \mathrm{~g})\end{array}$ & $\begin{array}{c}\text { TFs } \\
(\mathrm{mg} \mathrm{RE} / 100 \mathrm{~g})\end{array}$ \\
\hline Unripe & $9.33 \pm 0.19 \mathrm{a}$ & $11.50 \pm 0.00 \mathrm{c}$ & $29.80 \pm 0.06 \mathrm{c}$ & $737.73 \pm 0.88 \mathrm{a}$ & $13.81 \pm 0.09 \mathrm{c}$ & $58.17 \pm 1.29 \mathrm{c}$ \\
Intermediate & $6.69 \pm 0.10 \mathrm{~b}$ & $19.36 \pm 0.53 \mathrm{a}$ & $33.66 \pm 0.75 \mathrm{~b}$ & $129.89 \pm 0.73 \mathrm{~b}$ & $17.70 \pm 0.03 \mathrm{~b}$ & $121.71 \pm 2.20 \mathrm{a}$ \\
Ripe & $1.95 \pm 0.02 \mathrm{c}$ & $12.62 \pm 0.53 \mathrm{~b}$ & $40.13 \pm 0.26 \mathrm{a}$ & $37.54 \pm 0.26 \mathrm{c}$ & $23.83 \pm 0.09 \mathrm{a}$ & $137.05 \pm 0.72 \mathrm{~b}$ \\
$P$ & $<0.001$ & 0.002 & $<0.001$ & $<0.001$ & $<0.001$ & $<0.001$ \\
$R^{2}$ & 0.998 & 0.876 & 0.977 & 0.999 & 0.995 & 0.983 \\
\hline
\end{tabular}

Different letters in each column represent significant differences between the ripe stage $(P<0.05)$. All measures were performed in three independent samples.

different evolution pattern: while both unripe and intermediate fruits displayed higher values $(9.33 \pm 0.19$ and $6.69 \pm 0.10 \mathrm{~g}$ citric acid $/ \mathrm{kg}$ of extract, respectively), the ripe stage of ripe stage presented significant lower amounts of titratable acidity content $(1.95 \pm 0.02 \mathrm{~g}$ citric acid $/ \mathrm{kg})$. Review of the literature showed that the total acid varied from $0.79 \%$ at 20 days after flowering to $0.46 \%$ at 220 days after flowering (Mou et al., 1991). The mean total acid of $0.39 \%$ at yellow stage and $0.45 \%$ at the red stage of reported by She et al. (1988).

So far there has been no detailed report on the soluble protein content in Rosa laevigata Michx. Maturity stage significantly affected the soluble protein, soluble protein content was higher in intermediate stage in comparison with other two stages, ranging from 11.50 to $19.36 \mathrm{mg} \mathrm{BAE} / 100 \mathrm{~g}$. The reducing sugar content changed significantly during fruit ripening. Reducing sugar content of Rosa laevigata Michx increased and ranged from 29.80 to $40.13 \%$ during from unripe to ripe stage. This result is in agreement with that of Mou et al. (1991) who found that the reducing sugar content of Rosa laevigata Michx changed significantly during maturation and ripening.

The total ascorbic acid changed significantly during fruit ripening. Total ascorbic acid content ranged from 37.54 to $737.73 \mathrm{mg}$ AAE/100g fw from unripe to ripe stage. In comparison with the results obtained in the present study with total ascorbic acid content of harvest at 1986 and 1987 ranging from 69.27 to 1164.36 and 55.60 to $1210.22 \mathrm{mg} / 100 \mathrm{~g}$ fw during its growth and development, respectively, other researchers have reported lower or higher values for the different harvest time investigated. For instance, Mou et al. (1991) reported that vitamin $\mathrm{C}$ varied from 55.60 at 20 days after flowering to $1210.22 \mathrm{mg} / 100 \mathrm{~g}$ at 220 days after flowering. Yao \& She (1991) analyzed the vitamin $\mathrm{C}$ contents at different ripening stages from July to November and concluded that vitamin C contents changed significantly during ripening. The authors found that the vitamin contents reach the peak in the middle of October, which is the suitable time for harvest.

The total polyphenol content and total flavonoids content showed a different evolution pattern: while both unripe (13.81 $\mathrm{mg} \pm 0.09 \mathrm{mg}$ GAE/100 $\mathrm{g}$ and $58.17 \mathrm{mg} \pm 1.29 \mathrm{mg}$ $\mathrm{RE} / 100 \mathrm{~g}$ of extract, respectively) and intermediate fruits displayed lower values $(17.70 \mathrm{mg} \pm 0.03 \mathrm{mg} \mathrm{GAE} / 100 \mathrm{~g}$ and $121.71 \mathrm{mg} \pm 2.20 \mathrm{mg} \mathrm{RE} / 100 \mathrm{~g}$ of extract, respectively), the ripe stage of ripening presented significant higher amounts of total polyphenol $(23.83 \mathrm{mg} \pm 0.09 \mathrm{mg}$ GAE/100 $\mathrm{g}$ and $137.05 \mathrm{mg} \pm 0.72 \mathrm{mg} \mathrm{RE} / 100 \mathrm{~g})$. Statistically, it was observed that total polyphenol content changed during ripening of Rosa laevigata Michx. Interestingly, total flavonoids content decreased significantly at the final stage of maturity. In comparison with literature, the total flavonoids content was lower than those reported in the literature $(0.48 \%$ to $5.3 \%)$ by $\mathrm{Xu}$ et al. (2012) and Liu et al. (2013).

Table 1 also shows the correlation between ripening stage and the bioactive compounds. Higher titratable acidity content was found on the unripe fruits, and the content decrease as the maturation increases, a negative correlation was established. The very significant correlations were established between ripeness and bioactive compounds. For total ascorbic acid, a $P$ value of $<0.001$ was achieved, and for total flavonoids and total polyphenol content, the $\mathrm{P}$ values are $<0.001$, proving the extreme influence of the maturation on the bioactive compounds of Rosa laevigata Michx. For the first one, a decrease of its content is noticeable, as the ripeness increase, also proved by the obtained negative linear correlation. For the total flavonoids and total polyphenol content, a linear correlation was achieved, proving that their content increase with the ripening of fruit.

\subsection{Antioxidant activity}

Rosa laevigata Michx was analyzed for expression of the antioxidant activity, measured in EM60m extracts of different ripen stage by DPPH, FRAP, and TRPA. The antioxidant activity of EM60m extracts of the Rosa laevigata Michx fruit is described in Table 2. Rosa laevigata Michx in ripe stage showed the highest antioxidant activity compared to the other maturity stage when measured by DPPH $(47.58 \mu \mathrm{M}$ TE / g; P < 0.001), FRAP (11.85 $\mu \mathrm{M} \mathrm{TE} / \mathrm{g}$; $<$ 0.001), and TRPA (20.85 $\mu \mathrm{g} \mathrm{AAE/g;}$ $P<0.001)$ assays. By contrast, Rosa laevigata Michx in unripe stage exerted the lowest antioxidant activity when measured by DPPH, TRPA and FARP assays. Rosa laevigata Michx in ripe stage showed the highest ROS compared to the other maturity stage when measured by $\mathrm{O}_{2}^{-}(20.30 \pm 0.03 \% ; P<0.001), \mathrm{OH}^{-}$ $(70.95 \pm 0.39 \% ; P<0.001)$, and $\mathrm{H}_{2} \mathrm{O}_{2}(137.36 \pm 3.48 \% ; P<0.001)$ scavenging ratio assays (Table 2 ), and the lowest ROS at unripe stage. By contrast, Rosa laevigata Michx in intermediate stage exerted the lowest scavenging ratio when measured by $\mathrm{H}_{2} \mathrm{O}_{2}$, $\mathrm{OH}^{-}$and $\mathrm{O}_{2}^{-}$assays.

\subsection{Correlation coefficient evaluate}

Table 3 shows the correlation between antioxidant capacity and the bioactive compounds during different ripening stage. These findings mirrored the trend reported for all the studied bioactive 
Xie et al.

Table 2. Evolution of antioxidant activity and ROS during different ripe of Rosa laevigata Michx.

\begin{tabular}{lcccccc}
\hline & $\mathrm{DPPH}(\mu \mathrm{M} \mathrm{TE} / \mathrm{g})$ & $\mathrm{FRAP}(\mu \mathrm{M} \mathrm{TE} / \mathrm{g})$ & $\mathrm{TRPA}(\mu \mathrm{g}$ AAE$/ \mathrm{g})$ & SRSA $(\%)$ & HRSA $(\%)$ & HPSA $(\%)$ \\
\hline Unripe & $25.70 \pm 0.03 \mathrm{c}$ & $10.42 \pm 0.07 \mathrm{c}$ & $9.05 \pm 0.03 \mathrm{c}$ & $17.42 \pm 0.13 \mathrm{c}$ & $42.50 \pm 0.89 \mathrm{c}$ & $95.67 \pm 0.36 \mathrm{c}$ \\
Intermediate & $28.50 \pm 0.06 \mathrm{~b}$ & $11.50 \pm 0.15 \mathrm{a}$ & $19.85 \pm 0.03 \mathrm{~b}$ & $19.27 \pm 0.05 \mathrm{~b}$ & $48.56 \pm 0.59 \mathrm{~b}$ & $108.67 \pm 0.72 \mathrm{~b}$ \\
Ripe & $47.58 \pm 0.17 \mathrm{a}$ & $11.85 \pm 0.08 \mathrm{~b}$ & $20.85 \pm 0.08 \mathrm{a}$ & $20.30 \pm 0.03 \mathrm{ac}$ & $70.95 \pm 0.39 \mathrm{a}$ & $137.36 \pm 3.48 \mathrm{a}$ \\
$P$ & $<0.001$ & 0.002 & $<0.001$ & $<0.001$ & $<0.001$ & $<0.001$ \\
\hline \multicolumn{2}{l}{ Different letters in each column represent significant differences between the ripe stage $(P<0.05)$. All measures were performed in three independent samples. }
\end{tabular}

Table 3. Correlation coefficient of 13 indices.

\begin{tabular}{|c|c|c|c|c|c|c|c|c|c|c|c|c|}
\hline Indices & 1 & 2 & 3 & 4 & 5 & 6 & 7 & 8 & 9 & 10 & 11 & 12 \\
\hline $1 \mathrm{TAA}$ & 1 & & & & & & & & & & & \\
\hline 2TPC & -0.752 & 1 & & & & & & & & & & \\
\hline $4 \mathrm{SP}$ & -0.665 & $0.910^{\star *}$ & $0.930^{\star *}$ & 1 & & & & & & & & \\
\hline $5 \mathrm{TA}$ & $-0.972^{\star \star}$ & $0.885^{\star *}$ & $0.901^{\star \star}$ & $0.759^{*}$ & 1 & & & & & & & \\
\hline $6 \mathrm{RS}$ & 0.032 & 0.664 & 0.616 & $0.717^{\star *}$ & 0.261 & 1 & & & & & & \\
\hline 9 SRSA & $-0.960^{\star *}$ & 0.558 & 0.611 & 0.441 & $0.878^{\star *}$ & -0.198 & $0.954^{\star *}$ & -0.388 & 1 & & & \\
\hline $10 \mathrm{DPPH}$ & -0.680 & 0.037 & 0.102 & -0.078 & 0.495 & $-0.698^{\star}$ & 0.658 & 0.165 & $0.840^{* *}$ & 1 & & \\
\hline 11 HRSA & -0.417 & -0.279 & -0.205 & -0.355 & 0.192 & $-0.884^{\star *}$ & 0.385 & 0.468 & 0.625 & $0.946^{* *}$ & 1 & \\
\hline 12 HPSA & -0.307 & -0.365 & -0.316 & -0.506 & 0.093 & $-0.920^{\star *}$ & 0.285 & 0.562 & 0.528 & $0.897^{* *}$ & $0.974^{* *}$ & 1 \\
\hline
\end{tabular}

molecules (ascorbic acid, titratable acidity, total polyphenols, total flavonoids, and soluble protein, reducing sugar), which were constantly found in the highest amount in the fruit in ripe stage. A positive correlation between the antioxidant activity and the bioactive molecules was observed with TRPA and DPPH assays. The TRPA was strongly correlated with titratable acidity and total flavonoids $\left(R^{2}=0.979\right.$ and $R^{2}=0.809$, respectively), weaker correlation with total polyphenols content $\left(R^{2}=0.776\right)$, while strongly negative correlated with total ascorbic acid $\left(R^{2}=-0.999\right)$. The FRAP was strongly correlated with total polyphenols content and total flavonoids $\left(R^{2}=0.932\right.$ and $R^{2}=0.905$, respectively), weaker correlation with titratable acidity $\left(R^{2}=0.750\right)$, while strongly negative correlated with soluble protein and reducing sugar $\left(R^{2}=-0.928\right.$ and $R^{2}=-0.809$, respectively). Previous study has indicated that total flavonoids, total saponins from Rosa laevigata Michx against DPPH, APAP-induced liver injury, attenuating injury caused by $\mathrm{H}_{2} \mathrm{O}_{2}$, and hypolipidemic activity (Liu et al., 2010; Jia et al., 2012; Dong et al., 2014).

This study showed that the bioactive compounds of Rosa laevigata Michx changed significantly during on-vine ripening, with dramatic changes occurring during the transition to the last stage of ripe stage. The results achieved in this work may open the possibility of the use of Rosa laevigata Michx fruits as source of bioactive compounds, particularly those of ripe stage, and proper management of fruit ripening and harvesting are critical towards the optimization of bioactive compounds. They contain a considerable amount of bioactive compounds, as well as important against free-radicals and ROS, which combined with the fact that these fruits are a good source of ascorbic acid, flavonoids, polyphenol and reducing sugar, makes it as a promising sources of bioactive compounds. Furthermore, the production of Rosa laevigata Mich $x$ fruits derived products may also be of application for the pharmaceutical and food industries. The detected influence that maturation stage has on bioactive compounds content is of major importance, when considering this fruits as a possible industrial source of bioactive compounds, in order to achieve higher and viable yields.

\section{Conclusion}

Thereby, it was found that the content of titration acid and ascorbic acid is inversely proportional to the maturity. The contents of reducing sugar, total polyphenol and total flavonoids were directly proportional to the maturity. Antioxidant capacity and ROS inhibition are proportional to the degree of maturity, and the antioxidant capacity of Rosa laevigata Michx significantly increase during maturity. The Rosa laevigata Michx fruits at fully ripe stage had higher healthcare and medicinal value.

\section{Acknowledgements}

The authors would like to thank the Science and Technology Project of Department of Science and Technology of Guizhou Province (China) (Project LH[2014]7179) and Natural Science Project of Department of Education of Guizhou Province (China) (Project KY[2014]276) for financial support.

\section{References}

Cai, Y., Wang, S., Huang, S. J., Fang, L. Y., \& Ruan, W. F. (2011). Odor analysis odor of Rosa laevigata of different harvest time based on metal oxide sensors array electronic nose [In Chinese]. China Journal of Traditional Chinese Medicine and Pharmacy, 26(6), 1433-1435.

Cao, J. K., Jiang, W. B., \& Zhao, Y. M. (2007). Experiment guidance of postharvest physiology and biochemistry of fruits and vegetables [In Chinese]. Beijing: China Light Industry Press. 
Chen, N. F., \& Zhang, L. (2005). Study on the antioxidant property of flavonoid compound in Rosa laevigata Michx. Quarterly of Forest By-product and Speciality In China, 5, 2-4.

Dong, D. S., Xu, L. N., Han, X., Qi, Y., Xu, Y. W., Yin, L. H., Liu, K. L., \& Peng, J. Y. (2014). Effects of the total saponins from Rosa laevigata Mich $x$ fruit against acetaminophen-induced liver damage in mice via induction of autophagy and suppression of inflammation and apoptosis. Molecules (Basel, Switzerland), 19(6), 7189-7206. http:// dx.doi.org/10.3390/molecules19067189. PMid:24886943.

Dragović-Uzelac, V., Savić, Z., Brala, A., Levaj, B., Bursać Kovačević, D., \& Biško, A. (2010). Evaluation of phenolic content and antioxidant capacity of blueberry cultivars (Vaccinium corymbosum L.) grown in the Northwest Croatia. Food Technology and Biotechnology, $48(2), 214-221$.

Jia, Y. N., Liu, J., Zhang, S., Xu, L., Yin, L., Li, L., Zhao, Y. Y., \& Peng, J. Y. (2012). Total flavonoids from Rosa laevigata Michx fruit attenuates hydrogen peroxide induced injury in human umbilical vein endothelial cells. Food \& Chemical Toxicology An International Journal Published for the British Industrial Biological Research Association, 50(9), 31333141. http://dx.doi.org/10.1016/j.fct.2012.06.047. PMid:22771365.

Li, X., Cao, W., Shen, Y., Li, N., Dong, X. P., Wang, K. J., \& Cheng, Y. X. (2012). Antioxidant compounds from Rosa laevigata fruits. Food Chemistry, 130(3), 575-580. http://dx.doi.org/10.1016/j. foodchem.2011.07.076.

Liu, M., Xu, Y., Han, X., Liang, C., Yin, L. H., Xu, L., Zhao, Y. Y., Peng, J. Y., \& Sun, C. K. (2014). Potent effects of flavonoid-rich extract from Rosa laevigata Mich $x$ fruit against hydrogen peroxide-induced damage in pc12 cells via attenuation of oxidative stress, inflammation and apoptosis. Molecules (Basel, Switzerland), 19(8), 11816-11832. http://dx.doi.org/10.3390/molecules190811816. PMid:25105919.

Liu, X. G., Li, J. L., Gao, P. Y., \& Wu, Z. Y. (2013a). Recent Advances in Research on Edible Rosa laevigata Michx [In Chinese]. Food Science, 34(11), 592-597.

Liu, X. G., Zhang, W. C., Jin, M., Wu, Z. Y., Mu, X. K., \& Gao, P. Y. (2013b). Isolation and identification of triterpenes of fruit of Rosa laevigata Michx [In Chinese]. Journal of Shenyang Pharmaceutical University, 30(11), 851-857.

Liu, Y. T., Lu, B. N., Xu, L. N., Yin, L. H., Wang, X. N., Peng, J. Y., \& Liu, K.-X. (2010). The antioxidant activity and hypolipidemic activity of the total flavonoids from the fruit of Rosa laevigata Michx. Natural Science, 2(03), 175-183. http://dx.doi.org/10.4236/ns.2010.23027.

Liu,Y., Fu, Y., Li,L., \& Gao, Z.X. (2013) Orthogonal test preferred for extraction process of flavonoids in Rosa laevigata Michx [In Chinese]. Guangdong Agricultural Sciences, 2, 86-89.

Mou, J. F., Cai, J. T., Ding, Z. H., Tan, S. M., Wang, S. P., \& Luo, T. H. (1991). Studies on the relationship between phusiological changes and processing USE of the fruit of Rosa laevigata Michx [In Chinese]. J OF GAC, 10(1), 70-78.

Nuncio-Jáuregui, N., Munera-Picazo, S., Calín-Sánchez, Á., Wojdyło, A., Hernández, F., \& Carbonell-Barrachina, Á. A. (2015). Bioactive compound composition of pomegranate fruits removed during thinning. Journal of Food Composition and Analysis, 37, 11-19. http://dx.doi.org/10.1016/j.jfca.2014.06.015.

Oliveira, I., Baptista, P., Malheiro, R., Casal, S., Bento, A., \& Pereira, J. A. (2011). Influence of strawberry tree (Arbutus unedo L.) fruit ripening stage on chemical composition and antioxidant activity. Food Research International, 44(5), 1401-1407. http://dx.doi. org/10.1016/j.foodres.2011.02.009.

Opara, U. L., Al-Ani, M. R., \& Al-Rahbi, N. M. (2012). Effect of fruit ripening stage on physico-chemical properties, nutritional composition and antioxidant components of tomato (lycopersicum esculentum) cultivars. Food \& Bioprocess Technology, 5(8), 3236-3243. http:// dx.doi.org/10.1007/s11947-011-0693-5.

She, X. W., Li, L. G., Wang, P., \& Ouyang, Y. Z. (1988). Preliminary studies on the nutritive composition and the use of fruit of Cherokee rose [In Chinese]. Acta Horticulturae Sinica, 15(4), 240-244.

Tauchen, J., Marsik, P., Kvasnicova, M., Maghradze, D., Kokoska, L., Vanek, T., \& Landa, P. (2015). In vitro antioxidant activity and phenolic composition of Georgian, Central and West European wines. Journal of Food Composition and Analysis, 41, 113-121. http:// dx.doi.org/10.1016/j.jfca.2014.12.029.

Teixeira, R. S. S., Silva, A. S. A., Ferreira-Leitão, V. S., \& Bon, E. P. S. (2012). Amino acids interference on the quantification of reducing sugars by the 3,5-dinitrosalicylic acid assay mislead carbohydrase activity measurements. Carbohydrate Research, 363, 33-37. http:// dx.doi.org/10.1016/j.carres.2012.09.024. PMid:23103512.

Todorovic, V., Redovnikovic, I. R., Todorovic, Z., Jankovic, G., Dodevska, M., \& Sobajic, S. (2015). Polyphenols, methylxanthines, and antioxidant capacity of chocolates produced in Serbia. Journal of Food Composition and Analysis, 41, 137-143. http://dx.doi. org/10.1016/j.jfca.2015.01.018.

Xiao, K. J., Zhong, X. K., Wang, J., \& Jiang, J. G. (2011). Extraction of brown pigment from Rosa laevigata Michx and its antioxidant activities. Pharmaceutical Biology, 49(7), 734-740. http://dx.doi.or g/10.3109/13880209.2010.490948. PMid:21639686.

Xie, G. F., Tan, S. M., \& Yu, L. (2014). Effect of Calcium Chloride Treatment on Quality of Cowpea (Vigna unguiculata (L.) Walp). European Journal of Horticultural Science, 79(1), 16-21.

Xie, L. L., Zhang, M., \& Sun, J. C. (2011). Study on antoxidation activities of freezing blueberry polyphenol [In Chinese]. Journal of Food Science and Biotechnology, 30(6), 818-821.

Xu, C., Liu, S., Liu, Z., Song, F., \& Liu, S. (2013). Superoxide generated by pyrogallol reduces highly water-soluble tetrazolium salt to produce a soluble formazan: A simple assay for measuring superoxide anion radical scavenging activities of biological and abiological samples. Analytica Chimica Acta, 793, 53-60. http://dx.doi.org/10.1016/j. aca.2013.07.027. PMid:23953206.

Xu, P., Hu, S. L., Li, Y. Y., \& Shi, J. L. (2012). Comparison of polysaccharide and total flavonoids contents in Rosa laevigata Mich $x$ from different habitats [In Chinese]. China Pharmacist, 15(5), 648-650.

Yao, W., \& She, X. W. (1991). Study of changes of vitamin C and other nutrients of Cherokee Rose (Rose laegata) fruit at its stage of growth and development [In Chinese]. Journal of Central-sSouth Forestry College, 11(1), 93-97.

Zhang, S., Lu, B. N., Han, X., Xu, L. N., Qi, Y., Yin, L. H., Xu, Y. W., Zhao, Y. Y., Liu, K. X., \& Peng, J. Y. (2013b). Protection of the flavonoid fraction from Rosa laevigata Michx fruit against carbon tetrachloride-induced acute liver injury in mice. Food and Chemical Toxicology, 55, 60-69. http://dx.doi.org/10.1016/j.fct.2012.12.041. PMid:23279844.

Zhang, S., Qi, Y., Xu, Y., Han, X., Peng, J., Liu, K., \& Sun, C. K. (2013c). Protective effect of flavonoid-rich extract from Rosa laevigata Michx on cerebral ischemia-reperfusion injury through suppression of apoptosis and inflammation. Neurochemistry International, 63(5), 522532. http://dx.doi.org/10.1016/j.neuint.2013.08.008. PMid:24012531.

Zhang, S., Zheng, L., Dong, D., Xu, L., Yin, L., Qi, Y., Han, X., Lin, Y., Liu, K., \& Peng, J. (2013a). Effects of flavonoids from Rosa laevigata Michx fruit against high-fat diet-induced non-alcoholic fatty liver disease in rats. Food Chemistry, 141(3), 2108-2116. http://dx.doi. org/10.1016/j.foodchem.2013.05.019. PMid:23870935.

Zhao, Y. T., Guo, X. M., \& Li, F. Z. (2003). Antioxidative activity of polysaccharide from Rosa laevigata Michx. Journal of Biology, 20, 23-24. 